The Journal of SPORT, 2020, 8(1), 24-40

(C) Kent State University

\title{
Body Size Discrepancy and Eating Disorder Risk in Division I Cheerleaders
}

\author{
Brooke Bouza \\ University of Lynchburg \\ Christopher Blaszka \\ University of Arkansas \\ Sarah Stokowski \\ Clemson University \\ Stephen Dittmore \\ University of Arkansas \\ Brendon McDermott \\ University of Arkansas
}




\begin{abstract}
Women who are collegiate cheerleaders have strict appearance requirements which likely contributes to them having a higher prevalence of body image (BI) dissatisfaction and eating disorders (ED) risk than the general population. Men who are collegiate cheerleaders also have appearance requirements and may be at-risk; however, there is a gap in the literature regarding this specific population. Additionally, underclassmen cheerleaders may feel pressure to conform to the upperclassmen standards. Many collegiate cheerleaders do not have the same access to medical resources as athletes competing within the NCAA membership, leaving them vulnerable to undetected pathogenic eating behaviors. The purpose of this study was to examine BI dissatisfaction and ED risk in collegiate cheerleaders. Ninety-seven cheerleaders from 12 Division I universities completed the online survey. Risk of ED was demonstrated in $50 \%$ of women and $34 \%$ of men. Men and women were equally likely to experience body dissatisfaction $(\mathrm{p}=.407)$. Regarding the specific behaviors that identify someone as at-risk for an ED, there were few differences between men and women or underclassmen and upperclassmen. Therefore, it appears the unhealthy behaviors cheerleaders engage in are the same for everyone. Men and women cheerleaders both present a risk for ED above the general population. Men should no longer be ignored when examining these health behaviors.
\end{abstract}

\title{
Introduction
}

Collegiate cheerleading is categorized as an aesthetic sport (Byrne \& McLean, 2002; Sundgot-Borgen \& Torstveit, 2004; Torres-McGehee et al., 2009). In aesthetic sports or activities (dancers, swimmers, color guard, and majorettes, cross country, diving, figure skating, gymnastics and modern dance), the prevalence of eating disorder (ED) risk ranges from 24\%-73\%, compared to $9 \%$ of the general population (Anderson \& Petrie, 2012; Black, Larkin, Coster, Leverenz, \& Abood, 2003; Sundgot-Borgen \& Torstveit, 2004). Previously it was demonstrated that female athletes who competed in aesthetic sports had a greater risk for developing an ED compared to their male counterparts or the general public (Sundgot-Borgen \& Torstveit, 2004); however, more recent data suggests that in the athlete population, the difference between males and females regarding their risk for developing an ED was much smaller than previously thought (McDonald, Pritchard, \& McGuire, 2019).

Compared to other aesthetic sport athletes such as dancers, cheerleaders tend to be studied less often. Female cheerleaders report their coaches, referees, and the university all place pressure on them to maintain a small and lean figure 
(Beckner \& Record, 2016). The multilevel influence on these cheerleaders suggests this problem is woven into the college culture for these athletes, making it difficult for them to avoid such pressures. Previous literature on this topic discovered one-third of collegiate cheerleaders possessed at least one risk factor for EDs (Torres-McGehee, Monsma, Dompier, \& Washburn, 2012). Furthermore, despite the average collegiate cheerleader's BMI being categorized as normal or healthy, nearly all cheerleaders desired a smaller body size than their current healthy size (Monsma, Gay, \& Torres-McGehee, 2016; Torres-McGehee et al., 2012). These risk factors for EDs are not isolated to female cheerleaders. In a study of all male athletes from 19 different sports, cheerleaders had the highest prevalence of weight concerns out of all of the sports examined (Gorrell et al., 2019).

One unique characteristic of collegiate cheerleading is men and women are performing together on the same team. Although, negative body image and risks for developing an ED are recognized in women in sport (for a review see, Varnes et al., 2013), men who are cheerleaders may be under similar pressure to maintain a certain appearance. When competing in aesthetic sports, women are asked to be physically fit, petite, wear revealing clothing, and have "perfect" make-up and hair (Beckner \& Record, 2016; Grindstaff \& West, 2006). While the gender ideology for men in aesthetic sports is different. Men are expected to be physically strong and portray masculinity (Coakley, 2015).

It is possible these men may strive to portray their masculinity through their physical appearance as a result of their participation in a sport that is typically stigmatized as feminine (Grindstaff \& West, 2006).

Drawing on social comparison theory, which proposes there is a fundamental desire within individuals to evaluate themselves by comparing themselves and their abilities to others (Festinger, 1954; Lange, Kruglanski, \& Higgins, 2012), research has demonstrated that body comparison can be a risk factor for developing an ED (Tylka \& Sabik, 2010) and the likelihood of experiencing negative body image (Kumar Tiwari \& Kumar, 2015). Comparing oneself to someone superior with positive characteristics is known as "upward comparison." Young athletes may be at risk of comparing their bodies to the older, more experienced athletes and this comparison of bodies could increase their pathogenic behaviors.

The National Collegiate Athletic Association (NCAA) has regulations in place to protect and monitor athlete's weight loss and weight loss methods (e.g., banning certain dietary supplements), which are often used to alter body image (LaBotz, Griesemer, \& Council on Sports Medicine and Fitness, 2016). However, cheerleading is not an NCAA-endorsed sport, and, therefore, cheerleaders are not regulated by the same rules as athletes competing in the NCAA-sanctioned sports. In 2008, the NCAA and Varsity Brands, Inc, worked together to add cheerleading 
to the NCAA's Catastrophic Injury Insurance Program (NCAA, 2016). This program requires teams to have a certified safety-coach or advisor at practices and games but does not require any medical professionals to be present (Bonci et al., 2008). Due to cheerleading lacking legitimacy among the NCAA membership, cheerleaders are at a greater risk for undiagnosed or unrecognized health issues (Nakajima \& Valdez, 2013; Torres-McGehee et al., 2012). Finally, university cheerleaders are not required to complete the same preparticipation exams where athletes (in NCAA-sanctioned sports) are screened for risk factors associated with EDs (NCAA, 2009).

Despite cheerleading possessing many characteristics of an NCAA sport, it is not categorized as a sport by the NCAA (Sawyer, 2010). Cheerleaders often do not have access to the medical resources provided to NCAA athletes.

Cheerleading requires high physical and aesthetic demands (Ball, 2012) which may lead to cheerleaders experiencing an increased risk for developing an ED and issues with their body image. However, these health problems may go unnoticed because cheerleaders do not receive similar medical attention as NCAA athletes. While the risk of developing an ED and issues with body image are well documented in women who participate in aesthetic sports (Coelho, Soares, \& Ribeiro, 2010; Varnes et al., 2013), males are only recently receiving recognition as being at-risk for developing an ED (McDonald et al., 2019).

The current study aimed to (1) compare and describe body size discrepancy (which is indicative of body image dissatisfaction) and risk factors for having an ED or disordered eating between male and female cheerleaders from Division I athletics universities and (2) compare and describe body size discrepancy and risk factors for having an ED or disordered eating between underclassmen and upperclassmen cheerleaders in Division I athletics programs.

\section{Method}

This study employed a cross-sectional online survey design which was approved by the Institutional Review Board. The survey link was electronically sent to 63 Division I cheer coaches and program directors who were asked to share the survey with their athletes. The survey was accessible to participants for 30 days and reminder emails were sent 10 and 20 days after the initial email. Of the 63 original email invitations to coaches/program directors, 13 coaches/program directors agreed to participate, 3 declined to participate, and the remaining 47 coaches/program directors never responded. Ninety-seven athletes from 12 programs completed the survey (about 8 athletes per program). Therefore, this study had a $19.0 \%$ response rate from the original 63 programs. Of the 97 participants, $60(61.9 \%)$ identified as women. The average age of participants was 20.1 years (range: 18-25 years). 
The survey contained an informational page in which participants were informed that the survey would contain questions about disordered eating behaviors and body image dissatisfaction and would take 10 minutes to complete. Informed consent was documented when participants clicked an electronic link following the study description. Participants who agreed to take the survey first completed a demographics questionnaire (e.g., age and gender). Next, participants completed the Eating Attitudes Test-26 (EAT-26) (Garner, Olmsted, Bohr, \& Garfinkel, 1982), and Gender-Specific Silhouette Survey (Bulik et al., 2001).

\section{Measures}

Body mass index (BMI). Body mass index (BMI). Participants selfreported their height in inches and weight in pounds, which were used to calculate participant's BMI. The directions for scoring the EAT-26 were used to categorize participants as "very underweight", "underweight", or "normal or healthy" (Garner, 2010). If a participant is categorized as "very underweight "or "underweight" it means this person should seek attention from a medical professional because he or she is identified as at-risk for an ED, but this is not meant to diagnose them with an ED.

Eating Attitudes Test (EAT-26). This widely used standardized survey is a 26-item questionnaire employed to screen for ED risk and disordered eating characteristics (Garner et al., 1982). Items are measured on a 5-point Likert scale ranging from 'never' to 'always'. Reverse coding is used when required. This survey can be examined using a composite score of the 26 items or can be examined by three subscales: dieting (13 items) bulimia and food preoccupation (6 items), and oral control (7 items), which when added together comprise the total score. Higher scores on the individual scales indicate greater engagement in the behaviors that comprise the respective category. Individuals with a composite (total scale) score of 20 points or more on the EAT-26 are identified as at-risk for an ED and should consult a medical professional (Patton, Johnson-Sabine, Wood, Mann, \& Wakeling, 1990). Individuals with scores of 19 or lower are identified as likely not at-risk for an ED.

The EAT-26 survey also possesses five specific behavior items that would identify a participant as at-risk for an ED or disordered eating behavior. If participants indicate they engage in any of these behaviors, they are recognized as at risk for an ED. The behaviors include binge eating or losing control of food intake, vomiting after eating, the use of laxatives or diuretics for weight loss, exercising for more than one hour a day to lose weight, and having lost 20 pounds or more in the past 6 months. Therefore in this study, participants were flagged for being at-risk for having an ED if their BMI was categorized as "underweight" 
or " very underweight," their score on the EAT-26 was 20 or more, or if they answered yes to one of the five behavioral questions (Garner et al., 1982). Internal reliability for the EAT-26 composite score in our sample was high $(\alpha=.87)$, and in line with previous research from Garner et al., (1982) $(\alpha=.90)$.

Perceived and desired body image. The gender-specific BMI Figural Stimuli Silhouette Survey (SIL) (Bulik et al., 2001) was used to measure the participant's body size discrepancy which is indicative of a person's body image satisfaction. This is accomplished by asking participants to choose their perceived and ideal BMI, with the calculated difference between the two representing the body size discrepancy. Participants were presented with nine silhouettes which each correspond to a specific BMI, ranging from $18.3 \mathrm{~kg} / \mathrm{m}^{2}$ to $45.4 \mathrm{~kg} / \mathrm{m}^{2}$. To measure perceived BMI, participants were asked to "choose the figure that reflects how you think you currently look" by choosing the silhouette they identify with on a normal basis, or the "self-perceived body size." Then participants were presented with the same silhouettes and asked to, "choose your ideal body size" which was used to determine the participant's "ideal body size". Body size discrepancy was calculated by subtracting perceived body size from ideal body size. The greater the difference between "perceived" and "ideal" body size, the higher the "body size discrepancy value" which means low body image satisfaction. A negative number indicates a person wants a smaller body size than they think they currently have, and a positive number indicates a person wants a larger body size than they currently believe themselves to possess.

\section{Data Analysis}

Data analyses were conducted in IBM SPSS Version 24 and JAMOVI 0.9.1.12. Descriptive statistics for actual BMI, perceived BMI, ideal BMI, each of the three subscales on the EAT-26, the sum of EAT-26, body size discrepancy, and body size discrepancy only for those who wanted to have a smaller BMI were run. To provide both the frequentist error rates and relative evidence for each hypothesis, we utilized a Welch's t-test $(\alpha=.05)$ and Bayesian t-test (Cauchy prior $=0.707$ ), Bayesian factors between one and three indicate the data do not provide strong enough evidence to support differences between groups or not, otherwise known as ambiguous (Quintana \& Williams, 2018). These tests were then utilized to examine for differences in the outcome variables (actual BMI, perceived BMI, ideal BMI, subscales from the EAT-26, and body size discrepancies) between (1) men and women and (2) underclassmen and upperclassmen. As the majority of the participants wanted a smaller BMI, we ran just those participants in a separate test to show the magnitude of desired change and compare the magnitude between men and women, and underclassmen and 
upperclassmen for the subpopulation of people who wanted a smaller body size. The same was not run for people who wanted a larger BMI because each of those participants chose exactly an ideal silhouette one size larger than their perceived BMI silhouette, thus resulting in equal means and standard deviations.

Additionally, we examined the accuracy of choosing their perceived BMI silhouette to their actual BMI, understanding that a perfect match-up will not exist because there are only nine silhouettes to choose from and an infinite number of actual BMIs. To do this we took the absolute value of each participant's perceived BMI minus actual BMI. We then used the outcome of that subtraction for each participant and compared the accuracy between genders and education standing using a t-test with a Welch's correction.

Frequencies were calculated for the number of men and women and underclassmen and upperclassmen who possessed each of the ED risk factors. Fisher's Exact Tests were used to determine if there were differences in the distribution of the risk factors between (1) men and women and (2) underclassmen and upperclassmen. Fisher's Exact Tests were not conducted for the BMI risk factor and the risk factor of exercising for more than 60 minutes per day to lose weight because so few participants had those risk factors.

\section{Results}

Participant descriptive information can be found in Table 1. Forty-seven percent of the total sample were identified as being at-risk for an ED $(n=46)$; which included $50.0 \%$ of the women, $34.0 \%$ of the men, $46.8 \%$ of the underclassmen, and $48.0 \%$ of the upperclassmen. Means and standard deviations by gender and by education standing can be found in Table 1 and Table 2, respectively. Data in the present study indicated there is strong evidence that men were larger than women $\left(p<0.001, \mathrm{BF}_{10}=3.93 \cdot e^{11}\right.$; Table 3$)$ based on $\mathrm{BMI}$, and men had a higher ideal BMI compared to women $\left(p=0.002, \mathrm{BF}_{10}=19.66\right.$; Table 3$)$. Also, men had a significantly greater ( $p=0.016$, Cohen's $\mathrm{d}=-0.79$ ) body size discrepancy when examining only those who wanted a smaller body size; and there was moderate evidence for this finding $\left(\mathrm{BF}_{10}=9.07\right)$. Men perceived their BMI as larger compared to women (Cohen's $d=0.45$ ), but this was a nonsignificant difference $(p=0.058)$ and ambiguous of there being differences between genders $\left(\mathrm{BF}_{10}=1.68\right.$; Table 3$)$. However, there were no significant differences regarding dieting, bulimia and food preoccupation, oral control, the sum of the EAT-26, or body size discrepancy between genders ( $p>0.05$; Table 3$)$. Moreover, there was weak (i.e., $\mathrm{BF}_{10}$ between 0.33 and 1 ) evidence in favor of no differences between genders for these variables (Table 3 ). 
Table 1

Descriptive statistics by gender

\begin{tabular}{|c|c|c|}
\hline & $\begin{array}{l}\text { Women } \\
(\mathrm{n}=60)\end{array}$ & $\begin{array}{l}\text { Men } \\
(n=37)\end{array}$ \\
\hline & $\mathrm{n}(\%)$ & $\mathrm{n}(\%)$ \\
\hline Freshman & $18(30.0 \%)$ & $7(18.9 \%)$ \\
\hline Sophomore & $15(25.0 \%)$ & $7(18.9 \%)$ \\
\hline Junior & $15(25.0 \%)$ & $11(29.7 \%)$ \\
\hline \multirow[t]{2}{*}{ Senior } & $12(20.0 \%)$ & $12(32.4 \%)$ \\
\hline & $(\mathrm{M} \pm \mathrm{SD})$ & $(\mathrm{M} \pm \mathrm{SD})$ \\
\hline Age (years) & $19.83 \pm 1.54$ & $20.62 \pm 1.50$ \\
\hline Weight (Lbs.) & $123.13 \pm 15.06$ & $194.81 \pm 25.05$ \\
\hline Height (inches) & $62.55 \pm 2.66$ & $71.00 \pm 1.96$ \\
\hline Actual BMI $\left(\mathrm{kg} / \mathrm{m}^{2}\right)$ & $22.13 \pm 2.38$ & $27.12 \pm 2.97$ \\
\hline Perceived BMI $\left(\mathrm{kg} / \mathrm{m}^{2}\right)$ & $22.33 \pm 2.08$ & $23.53 \pm 3.39$ \\
\hline Ideal BMI $\left(\mathrm{kg} / \mathrm{m}^{2}\right)$ & $20.25 \pm 1.00$ & $20.93 \pm 1.02$ \\
\hline Dieting $^{\mathrm{a}}$ & $9.43 \pm 8.46$ & $7.46 \pm 6.69$ \\
\hline Bulimia and food preoccupation ${ }^{\mathrm{a}}$ & $1.68 \pm 2.63$ & $1.14 \pm 2.20$ \\
\hline Oral control $^{\mathrm{a}}$ & $1.47 \pm 2.21$ & $1.97 \pm 1.88$ \\
\hline SUM of EAT-26 & $12.58 \pm 11.01$ & $10.57 \pm 8.81$ \\
\hline Body size discrepancy & $-2.08 \pm 2.15$ & $-2.60 \pm 3.36$ \\
\hline Body size discrepancy ${ }^{b}$ & $-3.05 \pm 1.83$ & $-4.80 \pm 2.87$ \\
\hline
\end{tabular}

Table 2

Descriptive statistics by education status

\begin{tabular}{lll}
\hline & $\begin{array}{l}\text { Underclassmen } \\
(\mathrm{n}=47)\end{array}$ & $\begin{array}{l}\text { Upperclassmen } \\
(\mathrm{n}=50)\end{array}$ \\
\hline Women & $\mathrm{n}(\%)$ & $\mathrm{n}(\%)$ \\
\cline { 2 - 3 } Men & $33(55.0 \%)$ & $28(45.0 \%)$ \\
\hline & $14(37.8 \%)$ & $23(62.2 \%)$ \\
Age (years) & $(\mathrm{M} \pm \mathrm{SD})$ & $(\mathrm{M} \pm \mathrm{SD})$ \\
Weight (Lbs.) & $18.9 \pm 0.82$ & $21.3 \pm 1.23$ \\
Height (inches) & $144.0 \pm 37.7$ & $156.0 \pm 41.5$ \\
Actual BMI $\left(\mathrm{kg} / \mathrm{m}^{2}\right)$ & $64.9 \pm 4.76$ & $66.6 \pm 4.70$ \\
Perceived BMI $\left(\mathrm{kg} / \mathrm{m}^{2}\right)$ & $23.68 \pm 3.39$ & $24.36 \pm 3.74$ \\
Ideal BMI $\left(\mathrm{kg} / \mathrm{m}^{2}\right)$ & $22.71 \pm 2.91$ & $22.85 \pm 2.53$ \\
Dieting & $20.19 \pm 0.90$ & $20.81 \pm 1.11$ \\
Bulimia and food preoccupation & $\mathrm{a}$ \\
Oral control $^{\mathrm{a}}$ & $8.32 \pm 7.40$ & $9.02 \pm 8.32$ \\
SUM of EAT-26 $^{\mathrm{a}}$ & $1.04 \pm 1.98$ & $1.88 \pm 2.83$ \\
Body size discrepancy $_{\text {Body size discrepancy }}^{\mathrm{b}}$ & $1.53 \pm 1.99$ & $1.78 \pm 2.20$ \\
\hline
\end{tabular}

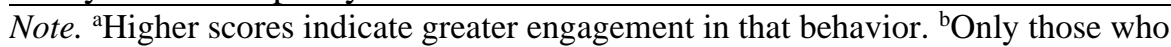
wanted a lower BMI were included. The mean indicates the change in BMI they wish to achieve. 
Table 3

Welch's t test and Bayesian t tests by gender

\begin{tabular}{llllll}
\hline & Cohen's d & $\mathrm{t}$ & $\mathrm{df}$ & $p$ & $\mathrm{BF}_{10}{ }^{¥}$ \\
\hline Actual BMI & 1.91 & 8.67 & 64.1 & $<.001$ & $3.93 \cdot e^{11}$ \\
Perceived BMI & 0.45 & 1.94 & 53.0 & 0.058 & 1.68 \\
Ideal BMI & 0.68 & 3.23 & 75.3 & 0.002 & 19.66 \\
Dieting & -0.25 & -1.27 & 89.1 & 0.206 & 0.42 \\
Bulimia \& food & -0.22 & -1.10 & 86.5 & 0.272 & 0.36 \\
preoccupation & 0.24 & 1.21 & 85.5 & 0.231 & 0.40 \\
Oral control & -0.20 & -0.99 & 88.6 & 0.323 & 0.32 \\
Sum of EAT-26 & -0.19 & -0.84 & 54.3 & 0.407 & 0.32 \\
Body size discrepancy & -0.79 & -2.56 & 28.4 & 0.016 & 9.07 \\
Body size discrepancy & &
\end{tabular}

Note. ${ }^{¥} \mathrm{BF}_{10}$ represents the Bayes Factor in favor of the alternative compared to the null hypothesis. ${ }^{a}$ Only those who wanted a smaller BMI were included in analysis.

Results of the comparisons between underclassmen and upperclassmen are shown in Table 4. Upperclassmen idealized smaller BMIs compared to underclassmen $(p=0.003)$, and there was small-moderate evidence in favor of them being meaningfully different $\left(\mathrm{BF}_{10}=10.13\right.$; Table 4$)$. However, there were no other differences between underclassmen and upperclassmen for perceived BMI, dieting, bulimia and food preoccupation, oral control, the sum of the EAT26, body size discrepancy, and body size discrepancy for those who wanted a smaller BMI. Additionally, the Bayesian t-test suggests evidence to support no differences between groups (i.e., $\mathrm{BF}_{10}$ between 0.22 and 0.74 ).

Table 4

Welch's $t$ test and Bayesian t tests by underclassmen and upperclassmen

\begin{tabular}{llllll}
\hline & Cohen's d & $\mathrm{t}$ & $\mathrm{df}$ & $p$ & $\mathrm{BF}_{10}{ }^{\mp}$ \\
\hline Actual BMI & -0.19 & -0.94 & 94.9 & 0.349 & 0.32 \\
Perceived BMI & -0.05 & -0.25 & 91.3 & 0.802 & 0.22 \\
Ideal BMI & -0.61 & -3.01 & 93.1 & 0.003 & 10.13 \\
Dieting & -0.09 & -0.44 & 94.7 & 0.662 & 0.23 \\
Bulimia \& food & -0.34 & -1.70 & 87.8 & 0.093 & 0.74 \\
preoccupation & -0.12 & -0.58 & 94.9 & 0.561 & 0.25 \\
Oral control & -0.17 & -0.86 & 93.1 & 0.390 & 0.30 \\
Sum of EAT-26 & -0.18 & -0.87 & 89.4 & 0.385 & 0.30 \\
Body size discrepancy & -0.05 & -0.21 & 57.4 & 0.838 & 0.26 \\
Body size discrepancy & & &
\end{tabular}

Note. ${ }^{¥} \mathrm{BF}_{10}$ represents the Bayes Factor in favor of the alternative compared to the null

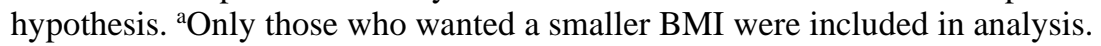


Women were significantly more accurate than men at choosing a perceived BMI silhouette with a BMI similar to their actual BMI $[\mathrm{t}(62.4)=5.37$, $\mathrm{p}<.001$, Cohen's $\mathrm{d}=1.19$ ]. Men were on average $3.81 \pm 2.06 \mathrm{~kg} / \mathrm{m}^{2}$ away from their actual BMI (or one full silhouette off), women were $1.68 \pm 1.59 \mathrm{~kg} / \mathrm{m}^{2}$ away from their actual BMIs (less than one silhouette off). There were no differences in the accuracy of choosing a perceived BMI silhouette close to one's own BMI between underclassmen and upperclassmen $[t(93.7)=-0.73, p=0.470$, Cohen's $d=-$ 0.147]. Underclassmen were $2.33 \pm 1.86 \mathrm{~kg} / \mathrm{m}^{2}$ away from their actual BMI and upperclassmen were $2.64 \pm 2.23 \mathrm{~kg} / \mathrm{m}^{2}$ or less than one silhouette from their actual BMI.

Gender-specific frequency of possessing each of the ED risk factors can be found in Figure 1. There were no significant differences between genders for EAT-26 score $(p=0.179)$, binge eating ( $p=0.770)$, vomiting to lose or maintain weight ( $p=1.00)$, use of laxatives, diet pills, or diuretics to control weight $(p=0.204)$, or 20 pounds of weight loss in the past six months $(p=0.102)$. No men had a BMI that classified them as underweight or engaged in excessive exercise to lose weight and only two and six women respectively, reported these behaviors.

Figure 1

Frequency of possessing ED risk factors by gender

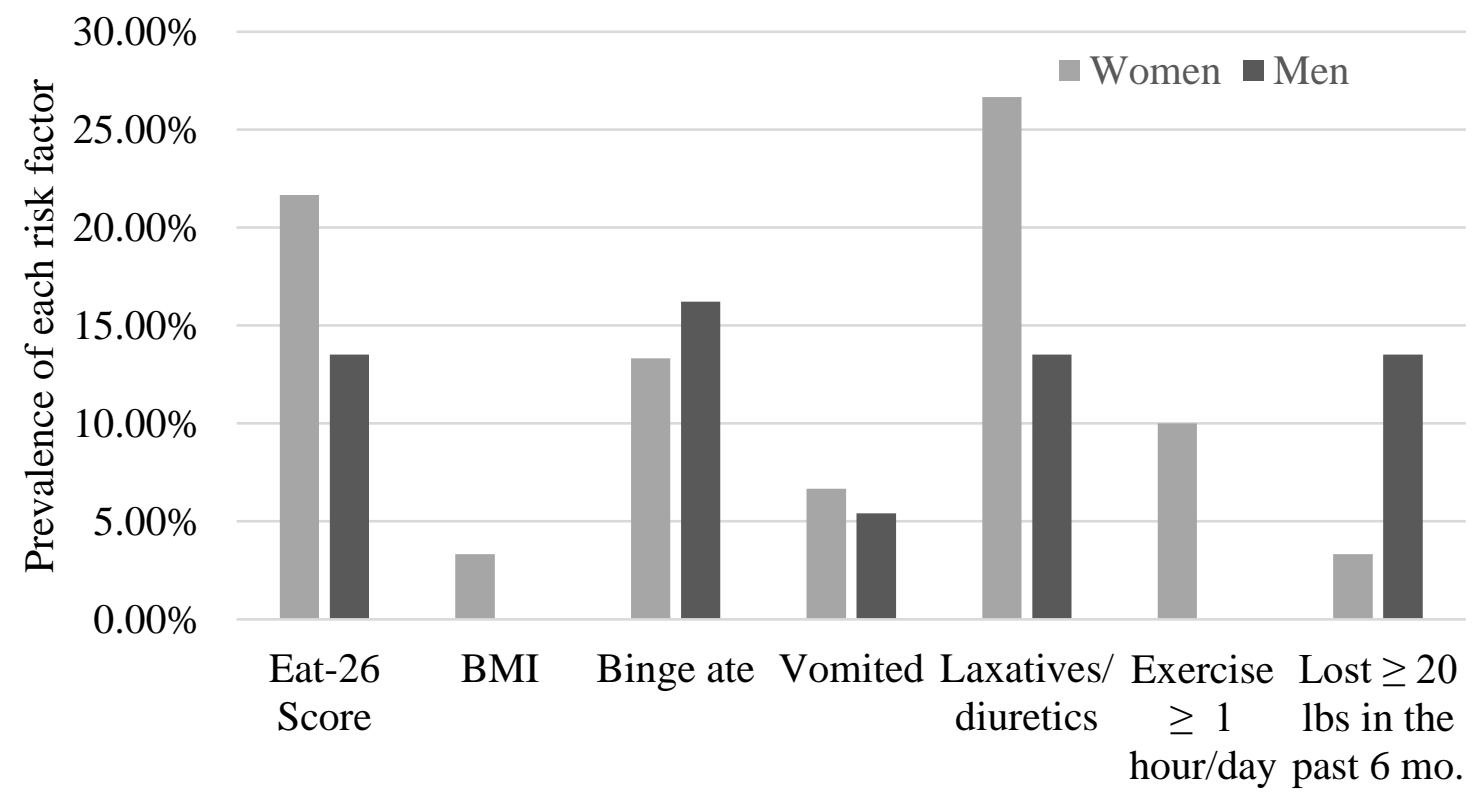

Figure $1 . * \mathrm{p} \leq .05$. Frequency of men $(\mathrm{n}=37)$ and women $(\mathrm{n}=60)$ for the presence of each factor that identifies an athlete as at-risk for an eating disorder. Exercise for one hour or more per day is specific only to those who perform the exercise with a goal of weight loss. 
Underclassmen- and upperclassman- specific frequencies of possessing at least one ED risk factor can be found in Figure 2. There were no differences between underclassmen and upperclassmen in distribution for EAT-26 $(p=1.00)$, exercising 60 minutes or more per day to maintain weight $(p=0.678)$, use of laxatives, diet pills, or diuretics to control weight $(p=1.00)$, vomiting to maintain weight ( $p=0.678$ ), or binge eating ( $p=0.361)$. Underclassmen were more likely to have lost 20 pounds in the past 6 months $(p=0.054)$. There were zero underclassmen and two upperclassmen that had a BMI considered to be at-risk for ED.

Figure 2

Frequency of possessing ED risk factors by underclassmen and upperclassmen
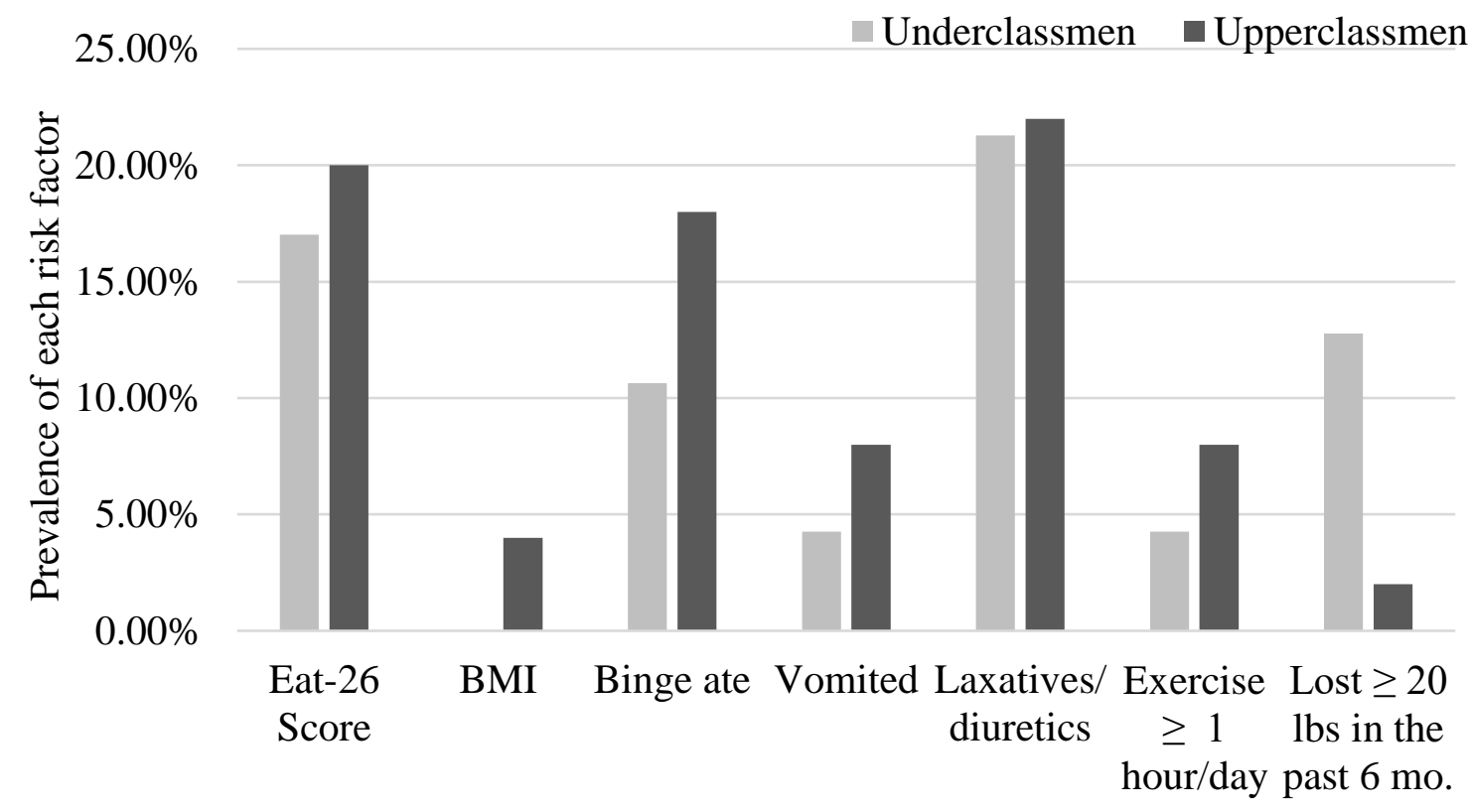

Figure 2. $* p=.054$ Frequency for underclassmen $(\mathrm{n}=47)$ and upperclassmen $(\mathrm{n}=50)$ for the presence of each factor that identifies an athlete as at-risk for an eating disorder.

Exercise for one hour or more per day is specific only to those who perform the exercise with a goal of weight loss.

\section{Discussion}

The objective of this study was to examine body size discrepancy and risk factors of having an eating disorder (ED) in cheerleaders at Division I universities. The prevalence of ED risk in other aesthetic sport athletes ranges 
from 24\%-73\%, (Black et al., 2003; Greenleaf, Petrie, Carter, \& Reel, 2009; Sundgot-Borgen \& Torstveit, 2004; Torres-McGehee et al., 2012). Further, cheerleaders who identify as men, who are regularly ignored in this body of literature, demonstrated ED risk above the rate in the general population, with $34.0 \%$ of the men in our sample possessing at least one ED risk factor. Moreover, when comparing just the cheerleaders who wanted smaller body sizes, men demonstrated greater body size discrepancy than women. The prevalence of possessing at least one ED risk factor and body size discrepancy were similar between underclassmen and upperclassmen.

The present study revealed a higher prevalence of ED risk in cheerleaders (47.42\%) than previous research (Torres-McGehee et al., 2012). One possible reason for our results demonstrating a higher prevalence of ED risk than previous research may be due to our entire sample being drawn from Division I programs as opposed to previous research by Torres-McGehee et al., (2012) who examined both Divisions I and II cheerleaders. Compared to Division II or III, Division I athletic events have the largest number of attendees and make up a disproportionate amount of college athletic media coverage.

The amount of exposure one gets from being present in third-party social media sources and the effects of that exposure on body image and risks of developing an ED have yet to be studied. However, when third-party social media posts a picture of an athlete, this athlete is exposed to a count of the number of "likes" the picture receives and public comments on the picture. Cheerleaders may be particularly vulnerable to objectifying comments when they are exposed in televised programs or social media. Future studies could examine cheerleader's media presence and risk for developing an ED.

Men in our study had greater BMIs than women. Men's average BMI categorized them as overweight and women's average BMI categorized them as normal or healthy per the National Heart, Lung, and Blood Institute standards (n.d.). It is unclear why men have significantly larger BMIs or the social and clinical significance of men's higher BMIs. It could be that these men strive for healthy muscle gain, which leads to a higher BMI, in order to have a more muscular or masculine appearance (Coakley, 2015). We did not measure body composition in this study and thus cannot speak to this sample's body composition. However, since our data indicate that $56.8 \%$ of men wanted a smaller BMI than their perceived BMI and of those men, the average desired decrease in BMI was $4.80 \mathrm{~kg} / \mathrm{m}^{2}$ less than their perceived BMI, we can conclude they wanted thinner bodies.

There were few differences between underclassmen participants and upperclassmen participants. While upperclassmen chose ideal BMIs that were significantly smaller than underclassmen, there was not much variance on this factor and more research into a cheerleader's ideal BMI by year of college should 
be conducted. Underclassmen and upperclassmen were not different in all other continuous outcome variables. Underclassmen may not be engaging in upward comparison and if they are, it is not resulting in them engaging in pathogenic eating behaviors any more frequently than their upperclassmen counterparts. The lack of differences between education standing demonstrated in this study corroborates previous work (Torres-McGehee et al., 2018).

Regarding the question, "Have you lost 20 pounds or more in 6 months?", six of the seven participants that answered, "yes" were underclassmen and five out of the seven were men. Men may experience an adjustment period to collegelevel athletic expectations, which results in rapid weight loss early on as a college cheerleader, though no differences in ED risk or body size discrepancy were observed. Thus, this weight loss does not seem to impact ED risk or body size discrepancy. Emerging college cheerleaders may need to be monitored for rapid weight-loss, but continual monitoring throughout their entirety of collegiate cheerleading to detect unhealthy weight-loss mechanisms that can have lifelong physical and mental health impacts is warranted.

\section{Future Research}

Of the participants who wanted smaller BMIs, men desired a greater reduction in their BMI compared to women. While our results appear to provide evidence that women desired overall smaller ideal BMIs than men, this finding should be further investigated in future research as we had very little variance in this outcome variable making it difficult to distinguish true differences. Future research should seek larger and more representative samples. Future research should also examine if the smaller BMIs cheerleaders want to achieve would be considered healthy or if desired BMI would be considered underweight. An investigation that considers ethnicity as an additional demographic variable is also warranted. Also, future research could examine the weight-loss methods that cheerleaders practice to achieve their goals, as some weight loss methods may be safer than others.

For example, unhealthy weight-loss mechanisms in this study included, nearly one-third of women and $10 \%$ of men using laxatives and diuretics to lose or maintain weight, while others reported excessive exercise or vomiting food consumed. Furthermore, future studies should consider involving instrumentation that considers body image investment (desire and distress with looking different than the ideal). 


\section{Limitations}

Although our sample came from across the nation, our sample size was limited. We received a total of 97 responses. However, despite nearly half of our sample presenting as at-risk for an ED, it is possible this is an underestimation of the actual problem. It is possible our sample may be biased towards teams without a history of ED as two coaches (from different universities) reported they did not feel comfortable participating as they did not want to trigger relapses in their athletes with a history of EDs. Thus, our sample may underrepresent teams with a history of serious ED health concerns.

\section{Strengths}

The strengths of this study include a sample of men and women. Too often research on ED risk and body image in athletes focused solely on women, however, our results show that men were at an elevated risk for pathogenic behaviors. Additionally, we employed a widely-used screening tool to measure ED risk. Using this screening tool is not exclusive to researchers or medical professionals. Thus, despite cheerleaders lacking access to the same medical resources as athletes participating in NCAA-sanctioned sports, the EAT-26 may be an easy tool for coaches to use to monitor each cheerleader's ED risk.

\section{Conclusion}

This study has provided insight into the prevalence of ED risks and body size discrepancy amongst cheerleaders in Division I universities. While women continue to demonstrate a greater prevalence of these issues, men warrant equal attention regarding ED risk. Men and underclassmen should be monitored for excessive or rapid weight loss and binge eating, while women should be monitored for excessive exercise and inappropriate laxative and diuretic use. The presence of a "safety-coach or advisor" may not be enough to care for the overall health of these individuals.

\section{References}

Anderson, C., \& Petrie, T. A. (2012). Prevalence of disordered eating and pathogenic weight control behaviors among NCAA division I female collegiate gymnasts and swimmers. Research Quarterly for Exercise and Sport, 83(1), 120-124. https://doi.org/10.1080/02701367.2012.10599833 
Ball, M. (2012). Sidelined no more: The athletic and aesthetic qualities of cheer. Physical \& Health Education, 77(4), 30-33.

Beckner, B. N., \& Record, R. A. (2016). Navigating the thin-ideal in an athletic world: Influence of coach communication on female athletes' body image and health choices. Health Communication, 31(3), 364-373. doi:10.1080/10410236.2014.957998

Black, D. R., Larkin, L. J. S., Coster, D. C., Leverenz, L. J., \& Abood, D. A. (2003). Physiologic screening test for eating disorders/disordered eating among female collegiate athletes. Journal of Athletic Training, 38(4), 286-297.

Bonci, C. M., Bonci, L. J., Granger, L. R., Johnson, C. L., Malina, R. M., Milne, L. W., ... Vanderbunt, E. M. (2008). National Athletic Trainers' Association position statement: Preventing, detecting, and managing disordered eating in athletes. Journal of Athletic Training, 43(1), 80-108. doi:10.4085/1062-6050-43.1.80

Bulik, C., Wade, T., Heath, A., Martin, N., Stunkard, A., \& Eaves, L. (2001). Relating body mass index to figural stimuli: Population-based normative data for Caucasians. International Journal of Obesity, 25(10), 1517-1524. doi:10.1038/sj.ijo.0801742

Byrne, S., \& McLean, N. (2002). Elite athletes: Effects of the pressure to be thin. Journal of Science and Medicine in Sport, 5(2), 80-94.

Coakley, J. J. (2015). Sports in society: Issues and controversies (Eleventh edition). McGraw-Hill Education.

Coelho, G. M. de O., Soares, E. de A., \& Ribeiro, B. G. (2010). Are female athletes at increased risk for disordered eating and its complications? Appetite, 55(3), 379-387. doi:10.1016/j.appet.2010.08.003

Festinger, L. (1954). A theory of social comparison processes. Human Relations, 7(2), 117-140. doi:10.1177/001872675400700202

Garner, D. M. (2010). Eating Attitudes Test (EAT-26): Scoring and interpretation [PDF file]. Retrieved from https://www.nyeatingdisorders.org/pdf/EAT26IntpretScoring-Test-3-20-10.pdf

Garner, D. M., Olmsted, M. P., Bohr, Y., \& Garfinkel, P. E. (1982). The eating attitudes test: Psychometric features and clinical correlates. Psychological Medicine, 12(4), 871-878.

Gorrell, S., Nagata, J. M., Hill, K. B., Carlson, J. L., Shain, A. F., Wilson, J., ... Peebles, R. (2019). Eating behavior and reasons for exercise among competitive collegiate male athletes. Eating and Weight Disorders Studies on Anorexia, Bulimia and Obesity. doi:10.1007/s40519-019-00819-0 
Greenleaf, C., Petrie, T. A., Carter, J., \& Reel, J. J. (2009). Female collegiate athletes: Prevalence of eating disorders and disordered eating behaviors. Journal of American College Health, 57(5), 489-496. doi:10.3200/JACH.57.5.489-496

Grindstaff, L., \& West, E. (2006). Cheerleading and the gendered politics of sport. Social Problems, 53(4), 500-518. doi:10.1525/sp.2006.53.4.500

Kumar Tiwari, G., \& Kumar, S. (2015). Psychology and body image: A review (Vol. 5).

LaBotz, M., Griesemer, B. A., \& Council on Sports Medicine and Fitness. (2016). Use of performance-enhancing substances. Pediatrics, 138(1), e20161300-e20161300. doi:10.1542/peds.2016-1300

Lange, P. A. M. V., Kruglanski, A. W., \& Higgins, E. T. (Eds.). (2012). Social comparison theory. In Handbook of theories of social psychology (pp. 460-479). Los Angeles: SAGE.

McDonald, A. H., Pritchard, M., \& McGuire, M. K. (2019). Self-reported eating disorder risk in lean and non-lean NCAA collegiate athletes. Eating and Weight Disorders - Studies on Anorexia, Bulimia and Obesity. doi:10.1007/s40519-019-00681-0

Monsma, E. V., Gay, J., \& Torres-McGehee, T. M. (2016). Body image, maturation, and psychological functioning in college cheerleaders. Translational Journal of the American College of Sports Medicine, 1(8), 71-81. doi:10.1249/TJX.0000000000000007

Nakajima, M., \& Valdez, J. M. (2013). Implementing athletic trainers for the management of cheerleading injuries. Journal of Physical Education, Recreation \& Dance, 84(1), 20-25. hdoi:10.1080/07303084.2013.744926

National Collegiate Athletic Association. (2009). 2008-09 Division I Manual, Constitution, Operating Bylaws, Administrative Bylaws.

National Collegiate Athletic Association. (2016). Cheerleading and risk management insurance coverage summary. Retrieved from http://www.ncaa.org/about/resources/insurance/cheerleading-and-riskmanagement-insurance-coverage-summary

National Heart, Lung, and Blood Institute. (n.d.). Classification of overweight and obesity by BMI, waist circumference, and associated disease risks. Retrieved January 4, 2019, from https://www.nhlbi.nih.gov/health/educational/lose_wt/BMI/bmi_dis.htm

Patton, G. C., Johnson-Sabine, E., Wood, K., Mann, A. H., \& Wakeling, A. (1990). Abnormal eating attitudes in London schoolgirls--a prospective epidemiological study: Outcome at twelve month follow-up. Psychological Medicine, 20(2), 383-394. 
Quintana, D. S., \& Williams, D. R. (2018). Bayesian alternatives for common null-hypothesis significance tests in psychiatry: A non-technical guide using JASP. BMC Psychiatry, 18(1). doi:10.1186/s12888-018-1761-4

Sawyer, T. (2010). Title IX and budgets in athletics. 81(3), 9-10.

Sundgot-Borgen, J., \& Torstveit, M. K. (2004). Prevalence of eating disorders in elite athletes is higher than in the general population. Clinical Journal of Sports Medicine, 14(1), 25-32.

Torres-McGehee, T., Dodson, K., Emerson, D., Pritchett, K., Moore, E., \& Kimmel, M. (2018). Examination of female athlete triad components in collegiate equestrian athletes. Medicine \& Science in Sports \& Exercise, 50. https://doi.org/10.1249/01.mss.0000537121.06200.5e

Torres-McGehee, T. M., Green, J. M., Leeper, J. D., Leaver-Dunn, D., Richardson, M., \& Bishop, P. A. (2009). Body image, anthropometric measures, and eating-disorder prevalence in auxiliary unit members. Journal of Athletic Training, 44(4), 418-426. doi:10.4085/1062-6050-44.4.418

Torres-McGehee, T. M., Monsma, E. V., Dompier, T. P., \& Washburn, S. A. (2012). Eating disorder risk and the role of clothing in collegiate cheerleaders' body images. Journal of Athletic Training, 47(5), 541-548. doi:10.4085/1062-6050-47.5.03

Tylka, T. L., \& Sabik, N. J. (2010). Integrating social comparison theory and selfesteem within objectification theory to predict women's disordered eating. Sex Roles, 63(1-2), 18-31. doi:10.1007/s11199-010-9785-3

Varnes, J. R., Stellefson, M. L., Janelle, C. M., Dorman, S. M., Dodd, V., \& Miller, M. D. (2013). A systematic review of studies comparing body image concerns among female college athletes and non-athletes, 19972012. Body Image, 10(4), 421-432. doi:10.1016/j.bodyim.2013.06.001 